\section{INFO: A program for computing information theory measures of communication}

WAYNE P. ASPEY

Department of Zoology and Microbiology

Ohio University, Athens, Ohio 45701

and

\section{ROBERT FEINSTEIN \\ Marine Biomedical Institute, University of Texas Medical Branch Galveston, Texas 77550}

Information theory is a quantitative approach particularly suited for studying complex communication systems. This convenient tool (1) allows quantification of information transfer, (2) facilitates sequence analysis of behaviors over time, either of short or long durations, (3) can predict and generate models simulating behavior, and (4) can be used in comparative studies of the evolution of communication systems to aid in speciesphylogenetic placement. Following the development of information quantifying formulae (Shannon \& Weaver, 1949 ) and the spread of information measurement from psychology (Miller, 1953) to ethology, information theory has been utilized to study animal communication processes, including the honeybee's dance (Haldane \& Spurway, 1954), chemical communication among fire ants to locate food (Wilson, 1962), and aggressive interactions among hermit crabs (Hazlett \& Bossert, 1965), mantis shrimp (Dingle, 1972), and grasshoppers (Steinberg \& Conant, 1974).

Collectively, these studies indicate that information theory deserves more attention from investigators concerned with animal communication because such techniques allow calculation of values that can be compared across species, regardless of the type of behavior or sensory modality involved. The program presented here calculates the observed and predicted transitional probabilities of all input variables, as well as 10 measures of information as defined and explained by Dingle (1972).

Description. The program INFO consists of two major segments. The first segment performs all calculations necessary for the subsequent information analysis, including determinations of observed and predicted transitional probabilities from the raw data matrix. This matrix is obtained by breaking down the complete sequence of exchanges during an interaction to a series of two-act sequences such that the initial acts are the horizontal rows and following acts are the vertical columns. For example, the four-act sequence A-B-C-D provides three two-act sequences: A-B, B-C, and C-D. The second segment of INFO computes the various information values $(\mathrm{H})$ as explained by Dingle (1972). The unit of measurement used to quantify information is the "bit" (abbreviation for "binary digit"), that amount of information required to choose between two equiprobable alternatives. Figure 1 illustrates the relationship among several $H$ values for data presented in Aspey (1974). In addition to the traditionally applied transmission formula, the normalization procedure introduced by Steinberg and Conant (1974) has been implemented as well. This method makes possible intra- and interspecies comparisons of information transfer when the behavioral repertoires being compared consist of a different number of elements.

Input. Input for INFO includes: (1) B, the number of behaviors (or variables) under investigation; (2) $R$, the number of rows (i.e., preceding behaviors); and (3) $\mathrm{C}$, the number of columns (i.e., following behaviors). The raw data matrix is entered by rows and consists of $\mathrm{R}$ rows and $\mathrm{C}$ elements per row.

Output. Output for INFO includes: (1) the sum total of entries in the raw data matrix; (2) sums and probabilities of all row and column marginal totals; (3) the transitional probability matrix; (4) the predicted transitional probabilities for all columns with chi-square values for each variable; (5) expected values for each cell of the $\mathrm{R}$ by $\mathrm{C}$ matrix, with linkages between any two variables labeled when the observed and expected values differ significantly by the method of Andrew (1956); (6) the raw data matrix; and (7) the information values, in bits, that include $H_{\max }, H(X), H(Y), H(X, Y)$, $H(Y, X), H(X / Y), H(Y / X), T(X ; Y)$, and $R$ from Dingle $(1972)$, and $t(X / Y)$ and $P(X) J(X ; Y)$ for each variable from Steinberg and Conant (1974).

Restrictions. INFO is limited to calculating first-order analyses from two-act sequences when data are cast in a preceding-following matrix. Consequently, the number

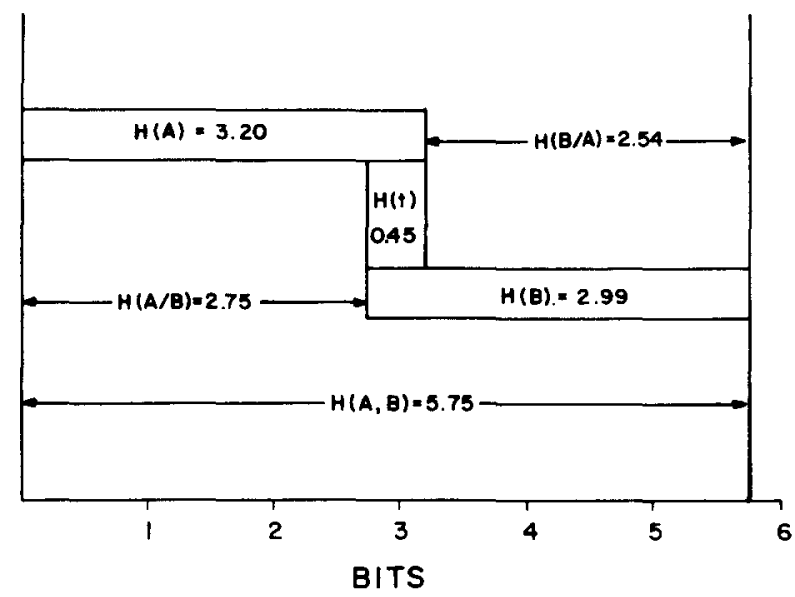

Figure 1. Relationships among various information values (H) calculated from agonistic interactions over 10 days from 40 adult male Schizocosa crassipes tested under varying density parameters. Data from Aspey (1974); figure adapted from Dingle (1972). 
of variables or behaviors under consideration must equal the number of rows and columns in the matrix.

Computer and Language. INFO was written in BASIC and FORTRAN IV. In BASIC, the program was developed on an IBM 360/44 computer using the OUIJI system (acronym for "Ohio University Instructional Job Interface") and implemented using the BASIC Assembler Interpretive Compiler at the Ohio University Center for Computational Services. In FORTRAN IV, the program was developed on a DEC PDP 11/45 computer at the Marine Biomedical Institute.

Availability. Copies of this paper, a descriptive source listing of the program INFO, and documented output from an illustrative example are available at no charge from Wayne P. Aspey, Division of Comparative Neurobiology and Behavior, the Marine Biomedical Institute, University of Texas Medical Branch, 200 University Boulevard, Galveston, Texas 77550.

\section{REFERENCES}

ANDREw, R. J. The aggressive and courtship behavior of certain Emberizines. Behaviour, 1956, 10, 255-308.
Aspey, W. P. Wolf spider sociobiology: An ethological and informational theory analysis of agonistic behavior in Schizocosa crassipes. Doctoral dissertation, Ohio University, December 1974.

Dingle, $H$. Aggressive behavior in stomatopods and the use of information theory in the analysis of animal communication. In Winn, H, E., \& Olla, B. L. (Eds.), Behavior of marine animals (Vol. 1). Invertebrates. New York: Plenum Press, 1972, 126-156.

Haldane, J. B. S., \& Spurway, H. A statistical analysis of communication in Apis mellifera and a comparison with communication in other animals. Insectes Sociaux, 1954, 1, 247-283.

HAZlett, B. A., \& Bossert, W. H. A statistical analysis of the aggressive communications systems of some hermit crabs. Animal Behaviour, 1965, 13, 357-373.

Mille R, G. A. What is information measurement? American Psychologist, 1953, 8, 3-11.

Shannon, C. E., \& WeAVer, H. The mathematical theory of communication. Urbana: University of Illinois Press, 1949.

Steinberg, J. B., \& Conant, R. C. An informational analysis of intermale behaviour of the grasshopper Chortophaga viridifasciata. Animal Behaviour, 1974, 22, 617-627.

Wilson, E. O. Chemical communication among workers of the fire ant Solenopsis saevissima (Fr. Smith). 2. An information analysis of the odour trail. Animal Behaviour, 1962, 10, 148-158. 